\title{
Pragmatics Electrified
}

\author{
Paolo Canal ${ }^{\bowtie}$ \\ paolo.canal@iusspavia.it \\ Valentina Bambini \\ valentina.bambini@iusspavia.it \\ Department of Humanities and Life Sciences \\ University School for Advanced Studies IUSS \\ Piazza della Vittoria 15, Pavia \\ Tel.: +39-0382-375841
}

\begin{abstract}
The electrical activity of the brain while elaborating linguistic material that is pragmatically charged surfaces in three ERP components (N400, P600/LPC, Sustained Negativity) and induced oscillatory changes. We present a qualitative, non-exhaustive, review of several empirical investigations that used EEG-based measures to investigate language processing in the pragmatic domain. Touching upon three main topics (non-literal language; discourse and conversation; clinical populations), we present the interaction of a set of cognitive processes that exploit semantic memory or elaborate on the mental representation of the current context to derive pragmatic inferences. ERP measures provide evidence for shedding new light on longstanding debates in pragmatics (e.g., the direct vs. indirect access issue), while a pragmatic perspective provides information on the functional role of ERP components (for instance to understand the nature of the P600 in nonsyntactic contexts).

Keywords. Pragmatics; Experimental Pragmatics; Metaphor; Idioms; Irony; Humor; Context; N400; P600; Sustained Negativity
\end{abstract}




\section{Contents}

1 From Grice to the electrodes 2

1.1 Pragmatics in a nutshell . . . . . . . . . . . . . . . . . 3

1.2 The electrophysiological landscape relevant for pragmatics . . . . . . . 4

2 Non-literal language $\quad 5$

2.1 EEG indexes for Lexical pragmatics . . . . . . . . . . . . . . 6

2.1.1 Functional interpretation . . . . . . . . . . . . . 8

2.2 EEG indexes for Mind reading pragmatics . . . . . . . . . . . . . 9

2.2.1 Functional interpretation . . . . . . . . . . . . . . 10

3 Context, discourse, and conversation $\quad 11$

3.1 Decomposing contextual factors . . . . . . . . . . . . . . . 11

3.2 Linking discourse . . . . . . . . . . . . . . . . . . 13

3.3 Conversation ........................... 14

4 ERP responses related to pragmatics in clinical conditions 16

5 Conclusions and future directions $\quad 17$

\section{From Grice to the electrodes}

In this chapter, we want to present an integrated and updated account of the brain's electrical correlates of language comprehension with a special focus on the processing of pragmatic phenomena. The study of language comprehension using the EEG has started in the eighties and, in the past decades, evidence has been accumulated allowing for a detailed description of the cognitive mechanisms involved in syntactic and semantic processing. The investigation of pragmatic phenomena has received less attention, but some of the 'core' pragmatic topics (e.g., contextual constraints and non-literal language) were already recognized as relevant research fields in two influential chapters devoted to "Psycholinguistics electrified" [1, 2]. In 2009, Van Berkum [3] raised attention on the electrical counterparts of pragmatic processing offering an overview of "The neuropragmatics of 'simple' utterance comprehension". We think it is time for a further update and expansion of the general framework encompassing pragmatics-related EEG effects.

After defining pragmatics through some core concepts and main research topics (Section 1.1), we will introduce the fundamental electrophysiological 'primitives' of language processing that are relevant for pragmatics (Section 1.2). Then we will link these two parts, by offering evidence on how different kinds of pragmatic phenomena modulate the electrical activity of the brain, trying to provide an integrated 
interpretation of the empirical findings (Sections 2 and 3), and providing a brief overview of the clinical literature (Section 4). Throughout the chapter, it will emerge that the set of electrical correlates of the brain is limited, that EEG based methods are extremely valuable to elucidate pragmatic processes and solve theoretical issues, and at the same time the study of pragmatics provides important evidence for better defining the cognitive processes underlying electrophysiological effects in general. These points and some remaining outstanding questions are addressed in Section 5.

\subsection{Pragmatics in a nutshell}

In his seminal book "Pragmatics", Levinson [4] provides a long list of possible definitions of the field, reflecting different philosophical and linguistic traditions from which the discipline originated. Although such a list might give the impression that the field lacks a precise identity and is a "wasted-paper" basket of what is left out by grammatical description of language [5], there is actually a common trait unifying all definitions of pragmatics: the attention to the context of use. Indeed, the most standard and comprehensive definition says that pragmatics is the study of language in a human context of use [6]. Pragmatics is thus the discipline that takes into account how language interacts with contextual factors, and as such it focuses on the communicative use of language. Most often, context is intended in a broad sense, including both linguistic factors (such as the previous discourse or conversation) and extralinguistic elements, from the physical setting to the psychological aspects of the interlocutors (world knowledge, emotions, beliefs, stereotypes, etc.) [7].

Eventually, contextual factors impact especially meaning interpretation, and some authors restrict the definitions of pragmatics in order to reflect this narrower view. For instance, Sperber and Wilson [8] define pragmatics as "the study of how linguistic properties and contextual factors interact in the interpretation of utterances". Likewise, Horn and Ward [9] state that "pragmatics is the study of the context-dependent aspects of meaning that are systematically abstracted away from the construction of the logical form". This perspective reflects the Gricean tradition in pragmatics, and it is based on the fundamental distinction between 'what is said' and 'what was implicated' by the speaker. Key notions in this focused sense of pragmatics are implicature (referring to the part of meaning which is implicated) and inference (referring to the cognitive operation supporting the derivation of implicatures) [10].

To study the effect of context on language, scholars in pragmatics normally focus on a set of topics which maximally display the gap between the literal and the intended meaning, such as non-literal language, or that depend on the large discourse, such as presupposition or anaphora. In this chapter we will adopt this coarse-grained distinction and describe the electrical correlates elicited by the processing of some non-literal phenomena (Section 2) and discourse phenomena (Section 3). Importantly, the research topics that will be described (e.g., metaphor or anaphora) have a consolidated tradition 
of psycholinguistic studies that is oriented towards semantic or grammatical accounts of language. Here, conversely, the phenomena at stake will be presented in a pragmatic frame, and their electrical correlates will be interpreted accordingly. A broader view of the ERP correlates of non literal language can be found in Chapter 17 in this volume.

\subsection{The electrophysiological landscape relevant for pragmatics}

The EEG technique allows investigating the mental chronometry of language comprehension processes by focusing on the behavior of ERP components [11]. Each ERP component can be thought of as the electrical reflection of the neural activity responsible for a specific cognitive mechanism, and it is characterized by a typical latency and scalp-distribution. In the temporal unfolding of the different ERP components, the $\mathrm{N} 400$ and the P600 play the most important roles in language processing [e.g., 12, 13, cf. Chapters 6-7].

The ERP literature on the N400, which is a negative deflection of the ERPs reaching a maximum at $400 \mathrm{~ms}$ from stimulus presentation in central parietal electrodes, has come to define a precise functional role to this component [14] and to identify the neural network supporting the associated cognitive mechanisms [15]: generally, the N400 component reflects the effort spent to retrieve conceptual knowledge from semantic memory when reading or listening to words in sentence or discourse, or even when processing non-verbal materials like line drawings or videos. Contextual information, as intended in the broadest sense (linguistic and extralinguistic) plays a major role in easing such operations of retrieval of conceptual information and thus modulates the amplitude of the N400. Being a hallmark of the influence of context on word processing, the N400 is very often involved in research on pragmatics.

The P600 component occurs a few hundred ms later, has a positive polarity, and reaches a maximum after $600 \mathrm{~ms}$. Differing from the N400, the functional meaning of the P600 is still debated. The component was first reported by Osterhout and Holcomb [16] for the processing of syntactic anomalies, suggesting that the elaboration of syntactic anomalies could be distinguished from the processing of semantic incongruities. While the association between the P600 amplitude and the processing of outright syntactic violations is not questioned, the functional role of the component is now more general. Indeed, ERP positivities occurring after the N400 have been associated with a range of non-syntactic phenomena: (i) semantic reversal anomalies of the kind The eggs were devouring ${ }^{1}$, which were expected to elicit N400 effects because involving thematic relations, were found to modulate the P600 instead [e.g., 17-19]; (ii) contextually less expected words, typically associated with larger N400, often modulated the amplitude of a following positivity, named Post-N400-Positivity

\footnotetext{
${ }^{1}$ When presenting example sentences from the EEG literature, we will underline the target word to which ERPs were time-locked and analyzed.
} 
(PNP) [for review, 20]); (iii) studies on figurative language, as we will see below, often reported positive ERP effects, sometimes associated with the P600 or the Late Positive Complex - LPC [e.g., 21]. All this evidence points to a role of the P600 in meaning interpretation. As such, also the P600 is often involved in research on pragmatics (cf. Chapter 7 for an in-depth discussion).

Studies on language comprehension also investigated the induced changes in EEG oscillations - the time-frequency (TF) domain of the EEG - looking for the functional role of oscillations across different frequency bands (cf. Chapter 8). This approach to studying language comprehension is in its adolescence and the attempts to provide a comprehensive account identifying the functional role of the different frequency ranges are recent [22-26]. Brain oscillations have been thoroughly investigated in the realm of speech processing, supporting the idea that different frequency ranges are involved in the segmentation of the speech input at the different levels of phonemes, syllables, or phrase boundaries, with frequency cycles of increasing length as a function of the length of the segment [e.g., 27].

Looking at comprehension processes, we sketch the following simplified scenario, focusing especially on the frequency ranges of relevance for pragmatics, and redirect the interested reader to the reviews above for a more detailed description: a power decrease of oscillations - corresponding to a desynchronization of neural activity - in the alpha range ( $\sim$ from 8 to $12 \mathrm{~Hz}$ ) has been observed across linguistic domains and is associated with increased cognitive demands [25], while synchronization - an increase in power in the alpha range was associated with the establishment of phrase dependencies [24]. Furthermore, changes in oscillations in the beta range ( $\sim$ from 12 to $30 \mathrm{~Hz})-$ which usually synchronize while reading correct and predictable sentences, and desynchronize for incoherent materials - are associated with the maintenance of the current cognitive set $[23,26]$ and may be linked with the generation of top-down predictions [24]. The gamma band ( $\sim$ above $35 \mathrm{~Hz}$ ) would instead be related to semantic processing, with semantic violations associated with a power drop, and this frequency range may interact with activity in the beta range providing a feedback for predictions by checking the incoming input [24]. Although the evidence is scant, all these frequency ranges have been implicated in pragmatic phenomena.

\section{Non-literal language}

In what follows we will provide a brief definition of each non-literal language phenomenon under scrutiny, before proceeding by illustrating the main evidence produced using the EEG methodology. People frequently use indirect ways to communicate. We naturally use irony and sarcasm to criticize someone or comment mockingly about a situation, we use humor to entertain our audience, we often make indirect requests to be polite, we use idiomatic expressions even when we are not able 
to trace back the origin of their meanings, and we exploit proverbs to express a piece of moral wisdom or metaphors to engage our interlocutor in searching the links between distant conceptual domains. From a pragmatic perspective, all instances of non-literal expressions represent a detour from compositional analysis, as it is not possible to derive their interpretation by simply combining the individual meaning of each word. The interpretation of these expressions is rather derived by filling the gap between what is said and what is meant through inferential processes that are part of speakers' pragmatic competence.

Idioms, like break the ice or spill the beans, are part of the family of noncompositional and highly conventional expressions that are sanctioned by usage [e.g., 28] and may vary along several dimensions [29], such as familiarity, semantic transparency, ambiguity, or syntactic frozenness. Proverbs, such as A rolling stone gathers no moss, are also fixed expressions, but they are full sentences, with a fully literal meaning along with the figurative one, that are used to communicate popular wisdom or social norms [e.g., 30]. Metaphors, such as the classic The lawyer is a shark, allow for a shift between conceptual domains [e.g., 31, 32] in which the properties of the vehicle (shark, i.e., the concept used to characterize the metaphor) are ascribed to the topic (lawyer, i.e., what is being talked about), and the dimension of novelty is particularly important [33]. In the pragmatic account proposed by Relevance Theory, these phenomena (although with some differences) fall within a spectrum of non-literalness and their inferential comprehension procedure involves specific sub-processes of adjustment and modulation of the lexically-encoded meaning [34], as the broadening and narrowing of the denotation of the literal meanings. We will therefore refer to these phenomena by using, with some liberty, the umbrella of "lexical pragmatics" [from 35, 36].

Compared to metaphors and idioms, irony and humor more radically engage the reader/listener in accounting for the speaker's communicative intentions. Traditionally, irony is a figure of speech where what is meant is the opposite of what is said, which can be thought of as the flouting of the maxim of truthfulness [37] or as an echoic statement that is used to express a derogatory attitude [38]. In verbal humor, the intention of the speaker is simply to amuse the audience and this is typically achieved by playing on a clash between contextual expectations and the punchline, that is, the opposition between alternative scripts [39]. Because of the key role of theory of mind mechanisms, we will group to these two phenomena under the novel term of 'mind-reading pragmatics'.

\subsection{EEG indexes for Lexical pragmatics}

Metaphors: The study of metaphors through ERPs was initiated by Pynte et al. [21]. Since then, more than forty studies have focused on sometimes very different aspects of metaphor processing. In the verbal domain, the most common ERP finding is that metaphors, when compared with matched literal stimuli, elicit a larger N400 component, 
both when metaphoric relations are tested using word pairs as tongue - viper versus tongue - saliva [e.g., 40-44], and when they are embedded in minimal sentence context, as Those fighters/animals are lions [e.g., 45-48]. N400 effects have also been observed when metaphors are presented in larger sentence contexts $[49,50]$ as well as in literary passages [51].

In a more limited number of studies, and especially when metaphors are embedded in sentences, the ERPs show a larger P600 or LPC for metaphoric as compared to literal stimuli [21, 47, 49, 52-55].

One point is worth noting here: the timing of the effects varies. It is often the case that ERP differences between kinds of metaphors, or between metaphors and literal conditions, were investigated by dividing the typical N400 time window into an early and a late portion [e.g., 45, 49]. Also P600 effects show variable timing, as well as different scalp distributions. Moreover, comprehension processes may also elicit sustained effects with a negative polarity, that were observed while processing novel [40, 56], creative [57], scientific [58], and literary [51] metaphors.

Idioms: Reading idiomatic expressions has been consistently associated with N400 effects, but in the opposite direction compared to metaphors. The N400 is reduced in amplitude [e.g., 59-61] when comparing idiomatic (e.g., Paolo had a hole in the stomach) with non-idiomatic sentences (e.g., Paolo had a hole in the shirt). It has also been observed that when expressions are recognized, readers anticipate the upcoming words with extreme confidence (take the bull by the... is very likely completed with the idiomatic word horns, even when the expression has no prior context): when predictions leave no room for uncertainty, processing the idiom constituent words is not associated with the N400 activity but with a different ERP component, the P300 (in idioms[61]; and in literal multi-word expressions [62]). Indeed, Rommers et al. [63] showed that the processes of composing the literal meanings of the idiomatic constituents may be switched off to some extent because the N400 is not as sensitive to semantic relatedness effects [64] as it is in literal contexts.

Idioms comprehension may also engage the P600. For instance, Canal et al. [59] showed that processing ambiguous idioms (i.e., having both a well-formed literal meaning and a figurative conventional meaning, such as break the ice) is associated with a frontally distributed and short-lived P600, rather than a N400 effect.

Two of the works previously cited investigated idioms processing in the time-frequency domain of the EEG [59, 63] and both consistently reported a power decrease in the higher gamma band (above $70 \mathrm{~Hz}$ ) for reading the same word embedded in idiomatic as compared to literal contexts.

Proverbs: ERP research on proverbs is scant but growing [e.g., 65-69]. Ferretti et al. [67] showed that when reading proverbs (e.g., Lightning never strikes the same 
place twice), the brainwaves associated with the target word showed a larger N400 for the figurative as compared to the literal context. No reliable LPC effects were found in this study, while instead the authors reported ERP differences at the level of slow cortical potentials - slow voltage changes $(<1 \mathrm{~Hz})$ in the ERPs that are typically studied across multiple word positions - developing just after reading the third word of the expression. Ferretti, Katz, et al. [68] further investigated the development of such slow drifts across sentence positions, while Ferretti, Hall, et al. [69] studied the effect of pragmatic markers (using literally or figuratively to comment the preceding proverb). Using a novel methodological approach, Bianchi et al. [65] focused on the comparison between the effect of predictability within "common" literal sentences, and sentences containing proverbs. In a way similar to what was observed in idioms [63], they reported that the N400 sensitivity to more or less predictable words was not preserved within proverbs. Overall, work on proverbs (and idioms) also highlighted the importance of the position factor in figurative language research: expressions are composed of more than one word, and it is often useful to look at the EEG signal changes across word positions.

\subsubsection{Functional interpretation}

When we consider together the ERP evidence described above, the main finding is that, compared to literal language, most figurative expressions engage N400-related processes. There are two main ways of interpreting this finding in a pragmatic perspective.

First, the increase in the N400 amplitude reflects the effort spent in retrieving and adjusting the meaning of the words constituting the figurative expression, which is maximal in metaphors and reduced in idioms. This view is compatible with the standard psycholinguistic interpretation of the N400 as linked to semantic memory [14] and it also fits with the pragmatic view in which figurative language requires lexical adjustment processes where conceptual properties are retrieved, selected and modelled upon the communicative situation [36]. The often reported larger N400 for novel as compared to conventional metaphors [e.g., 40, 44, 45] strongly support this view, because the differences between these types of metaphors concern their lexical status, with novel metaphors requiring to build meaning on the fly. Moreover, the N400 behavior in idioms [63] and proverbs [65] supports the idea that when it is not necessary to fully elaborate word meanings, word-by-word compositional processes are switched off to some extent.

The second relevant interpretation of the N400 effects observed for figurative language revolves around the role of context. Context has a facilitatory effect on pragmatic interpretation and meaning construction processes, reducing the N400 amplitude. The study of Bambini, Bertini, et al. [52] explicitly supports this view, since the N400 for metaphors was suppressed when a more supportive (compared to a 
minimal) context was provided. Similar findings were found also for another figurative type, namely metonymic expressions [70, 71]. Results from idioms further align with this context-related interpretation of the $\mathrm{N} 400$, showing that, when the upcoming input is predictable the N400 amplitude is hampered, and rather the brain response surfaces as a P300 pointing to the processing ease of pre-fabricated strings of words [61].

P600/LPC effects are less pervasive and this makes their interpretation more problematic. Coulson and Van Petten [53] first proposed that, in metaphor comprehension, the positivity could be linked to the recovery of additional semantic information after the initial semantic mismatch, but this view has been abandoned as metaphor novelty more clearly affects the N400 rather than the P600/LPC [e.g., 40, $44,45,56]$. De Grauwe and colleagues [49] interpreted the P600 effects as due to a continued reanalysis of the sentence meaning needed to solve the conflict between the literal and the metaphoric sense of the vehicle and to derive the final interpretation. Compatibly with this view but in a more pragmatic vein, Bambini, Bertini, et al. [52] interpreted the P600 as an inferential marker, namely the component reflecting the derivation of the implicature and the final meaning of the figurative expression. Their findings, in which P600 effects were found independently of whether the metaphor had sufficient ground or not, support this idea. Other support comes from the findings on metonymy [70, 71] and on ambiguous idioms [59], which may engage the cognitive system in additional processing effort possibly due to handling the ambiguity of the string and/or to derive the final interpretation of the sentence. It is interesting to note that the P600 does not surface in those cases where a definite interpretation is not reached due to the open-endeness of metaphors, such as in the case of literary metaphor, where the N400 is followed by a negativity which is sustained in time until $900 \mathrm{~ms}$ [51]. Conversely, as we will see in the next section, the P600 is a pervasive finding in mind-reading pragmatics phenomena.

The study of the frequency domain of the EEG in relation to figurative language is clearly undeveloped. The only two studies that ventured in this field, however, consistently point to power changes in the high gamma domain $(>70 \mathrm{~Hz})$, which are linked to the reduced engagement of semantic composition processes in idioms.

\subsection{EEG indexes for Mind reading pragmatics}

Irony: Several EEG studies on irony compared the processing of the same sentence embedded in either a literal or an ironic context. P600 effects are the most prominent across studies and are found in all works [e.g., 72-75] except those focusing on prosodic differences outside of context [76, 77]. Interestingly, P600 effects could be detected across communicative styles and task demands [72], with or without ironic cues [75], in positive, negative, or unusual contexts [78, 79], and when using emojis [80]. Such positive effects are often long-lasting and are sometimes taken to involve the LPC [78, $80,81]$. Conversely, N400 effects are present only in a limited set of cases, for instance 
when irony is used in a positive context (ironic praise) $[78,82,83]$ - commenting What a sad prize!, after winning a huge sum of money - and in more "unfamiliar" forms of irony [79]. It is also worth noting that it is not unlikely to find that irony induces even earlier effects in the ERPs, often involving the P200 component [e.g., 73]. Two studies in the literature on irony [74, 81] investigated the time-frequency domain of the EEG. A common finding concerns a power decrease in the alpha range, pointing to the idea that ironic sentences require the recruitment of more cognitive resources than literal sentences. A power increase associated with the theta and the gamma ranges was observed in Spotorno et al. [81].

Humor: Concerning humor, several studies tested the reading of canned verbal jokes and most of them involved a comparison between humorous and non-humorous sentences or dialogues - When I asked the bartender for something cold and full of rum, he recommended his wife versus ... he recommended his daiquiri [84]. Compared to straightforward conditions, the comprehension of humorous passages show a complex pattern of ERP effects, very often involving two or more different components. The effect that is first encountered shows a negative polarity: it is taken to involve the N400 [e.g., 84-87], or the Left Anterior Negativity (LAN) [e.g., 84, 88, 89]. After the initial negativity, the majority of studies reported positive effects on the ERP response, from relatively early occurring effects on the P600 $(500$ to roughly $750 \mathrm{~ms})[88,90]$ to later occurring differences associated with the LPC $[86,88]$.

Studies on humor processing rarely explored the time-frequency domain of the EEG. One single study focused on verbal materials and observed a power decrease in the beta range of the EEG [88]. When processing visual stimuli, the involvement of several frequency ranges [91] or a specific role for alpha oscillations and creative cognition in humor [92] was found.

\subsubsection{Functional interpretation}

It is undoubted that studies on irony and humor show a major involvement of the P600 and the LPC components. While the role of the P600 reported for metaphors and idioms is debated, the positivity for irony and humor is consistently interpreted as reflecting the inferential activity required to reverse sentence meaning in irony, or to resolve the humorous clash. On the one hand, this is in line with theoretical description that irony and (to some extent) humor involve the ability to account for the speaker's intentions, and that in both cases the final interpretation is very distant from the literal message (in irony) or from the expectations fed by the joke set up (in humor). On the other hand, it also adds to the idea that the cognitive mechanisms underlying the P600 deal with meaning, especially when sentence interpretation must be revised and/or the reader/listener must get the implicature (as proposed for metaphor). 
The N400 findings confirm the view that humor and to a limited extent irony involve the experience of a difficulty in connecting the incoming words with the expectations set up by the previous context. In irony this happens only when it is used in unusual way (see unfamiliar irony [79] or ironic praise [78]); in humor, the N400 may be involved in detecting the message incongruity that is fundamental for the humorous effect, and a similar role may be played by the Left Anterior Negativity, which typically reflects incongruity detection in the syntactic domain [e.g., 93].

Concerning humor, the observed multi-phasic ERP response (LAN/N400, P600 and LPC) captures the classic distinction between the different processing steps in humor comprehension [94]: incongruity detection (LAN/N400) and resolution (P600), and finally an elaboration/appreciation stage (LPC) [95].

The investigation of the time frequency domain of the EEG in mind reading pragmatics further adds that irony is cognitively engaging (alpha suppression [74, 81]) and that, after the resolution of a humorous clash, the mental representation of the discourse built so far is abandoned (beta suppression in [88]), favoring the transition to the third step of elaboration and appreciation.

\section{Context, discourse, and conversation}

\subsection{Decomposing contextual factors}

The idea that contextual information, especially intended as information from the previous linguistic context, plays a major role in language comprehension is widely accepted since behavioral work on the processing of ambiguous words [e.g., 96, 97]. Already back then it was clear that contextual information sets up rather specific expectations about upcoming words, and these expectations ease the comprehension of congruent words. This line of research largely benefited from the ERP methodology, and especially from the discovery of the N400 component [98], which paved the way to the study of the effect on comprehension of several contextual factors, and made the notion of cloze-probability of a word [99] very popular. Cloze-probability is the probability of a particular word to be used to complete a truncated sentence, which is robustly (and negatively) correlated with the size of the N400: less predictable words in the sentential context elicit larger N400 [14]. However, the unitary notion of cloze probability must not make us forget that many different factors contribute to making a word more or less predictable. From a pragmatic and psychological perspective, the notion of context is multifaceted, and both linguistic (e.g., sentence-level expectations, discourse information) and extralinguistic (individual knowledge or beliefs) factors, all together, contribute to creating expectations about what is next in the sentence.

Considering linguistic factors, the information provided by the prior sentence or discourse context is a primary source for semantic expectations. Federmeier and Kutas 
[64] showed that expectations can be rather specific and that the N400 not only measures the distance between context and incoming input, but can also be used to investigate the organization of semantic memory. In a typical experiment the processing of strongly expected words (e.g., brain) in context (He was afraid that doing drugs would damage his...) is compared to the processing of words that are similarly less predictable, but share some semantic features with the expected word (the related word e.g., mind), or not (the unrelated word e.g., reputation): the N400 is sensitive to this feature overlap and unrelated words show larger N400 when compared to related words (similar contextual effects have been extensively studied and reviewed by Van Petten and Luka [20]).

One more aspect that was revealed by the behavior of the N400 is that many different kinds of information that go "beyond the sentence given", as Hagoort and Van Berkum [100] would say, are part of the context in which a communicative exchange occurs, and they affect the N400, as local (sentence-level) sources of information do. Our knowledge about the speaker or the facts in the world affect the amplitude of the N400, which peaks when we hear a child voice uttering Before sleep I always drink a glass of wine [101, 102], or when we read the sentence The Dutch trains are white knowing that they are yellow [103]. Recently, Troyer and Kutas [104] further found that the N400 is also sensitive to encyclopedic knowledge, showing that individuals who better know Harry Potter's story also show larger N400 to sentences presenting wrong information about the characters. Discourse context is then capable of overriding semantic features. Actually, Nieuwland and Van Berkum [105] showed that animacy violation, such as The peanut was in love, which are expected to elicit an N400 effect when presented outside a context, do not elicit incongruity effects when the preceding context is fictive and describes a singing and dancing peanut. The N400 is also involved in processing statements that are inconsistent with one's moral attitude, like for a strict Christian being presented with I think euthanasia is an acceptable course of action [106].

N400 effects are often followed by later occurring positive effects which are also sensitive to the context, especially when processing unexpected but plausible words: Van Petten and Luka [20] proposed that they reflect the attempt of repairing or revising the sentence interpretation, after predictions turned out to be wrong. Moreover, the involvement of the Late Positive Potential - LPP which is typically associated with the processing of emotion - has been reported when investigating morally objectionable statements [106-109] and insults [110].

Concerning the time frequency domain of the EEG, words that are unexpected in context are typically associated with increased power in the theta band, when comparing high and low cloze sentences [e.g., 111]. World knowledge violations are instead associated with increased power in the theta and in the gamma range of the EEG when compared to correct sentences [e.g., 112] but not in natural reading [113]. 


\subsection{Linking discourse}

Linguistic information provided by the discourse context becomes part of the mental model of the discourse [e.g., 114]: forthcoming information must be integrated with it, by linking facts and characters to the different events described. One of the tools that mostly allows speakers to maintain a coherent representation of the ongoing discourse is anaphora. Anaphoric expressions, such as pronouns or nouns connecting the subsequent occurrences of the same referent in a text, have been widely investigated with ERPs (reviewed in Callahan [115]): these studies have shown that when semantic or grammatical features control agreement and make it impossible to link anaphoric expressions to an antecedent (The king prepared herself* for the dinner), a P600 is observed [116-118] attesting the "failure to agree"; conversely, N400 effects have been associated with the unexpected use of anaphoric expressions, as for instance for repeated names [119]. The case of ambiguous reference, that is, when there are more than one plausible antecedent for an anaphoric expression, is of special interest for pragmatics, because it may require a further search in the mental model to eventually choose the appropriate referent. Referential ambiguity was found to be associated with a different component, named Nref, which has a negative polarity, is long lasting, and has an anterior distribution [120-123]. Effects on this component are also found when processing unbound pronouns with no explicit antecedents [124], or when co-indexation features are computed on the basis of stereotypical gender [116].

Important evidence on anaphoric expressions comes from the study of givenness: very often information about the antecedents of a referring expression is not explicitly given, but can be inferred from the context. Burkhardt [125] recorded the ERPs while participants read sentences such as He said that the conductor was very impressive, preceded by three kinds of contexts: in one, the given condition, the referent was mentioned explicitly (Tobias visited a conductor in Berlin); in the second, the new condition, the referent was not mentioned (Tobias talked to Nina); lastly, in the bridged condition, the relationship between the two sentences could be derived via pragmatic inference (Tobias visited a concert in Berlin). The results showed that the differences in the ERPs concerned a reduction of the N400 amplitude for given as compared to new referents, while a larger P600 characterized the difference between bridged and given conditions. On the basis of this and other findings [e.g., 126] Schumacher [127] proposed that the N400 and the P600 would reflect Discourse Linking and Discourse Update mechanisms, respectively: the $\mathrm{N} 400$ would be related to the availability of the antecedent for a referring expression, allowing to establish the link between different entities of the discourse; the P600 would be associated with the structural consequences of an update of the discourse representation, obtained through the correction, modification or enrichment of such representation. Support for this view comes from the study of presupposition, which can be considered as a special case of referential expression, when reference is implicitly made to something that should, or 
is assumed be, common knowledge between interlocutors. Masia et al. [128] contrasted the processing of new information when "packaged" as presupposed (for instance, through a definite description: The migration was confirmed by a very recent article) or explicitly asserted as new (There was a migration, confirmed by a very recent article) embedded in naturalistic discourse contexts (e.g., It is by now well established that the humankind is not pure. In fact, our DNA contains genetic information belonging to Neanderthals, who soon peopled Europe). Results showed that when new information is presupposed, a larger N400 is observed. In Domaneschi et al. [129] the same target sentence (e.g., Due to overstaffing problems, about a month ago the graphic designer was made redundant) was presented following a context in which no information was given about the referent and therefore the presupposition needed to be accommodated in the discourse representation (In Paolo's office there are many employees), or following a context in which the antecedent was explicit and the presupposition "satisfied" (In Paolo's office, there used to be a very bad-tempered graphic designer). Overall, the accommodation of presupposed information induced a larger N400 followed by a larger P600. These results fit with the account of Schumacher [127]: when the effort mainly consists in tracking new information given as presupposed [128] the N400 increases, whereas, when the effort requires the update of the discourse model to accommodate the presupposed new information and consequently correct, or change the discourse representation a P600 is observed [129].

\subsection{Conversation}

Perhaps all research in psycho/neurolinguistics should aim at describing language processing in a naturalistic environment [130], and arguably conversation is the most natural environment for the use of language. Studying conversation in a laboratory setting where researchers try to get control over a range of confounding variables connected to the rich context in which conversation occurs is challenging. However, there are some interesting attempts, using for instance multiple modalities to realistically represent the large set of conversational features that is typical of communicative exchanges [e.g., 131].

One line of research in the domain of conversation concerns speech acts, that is, those actions that we perform using language, such as asking a question or giving an order [132, 133]. A number of studies have addressed the processing mechanisms underlying the two categories of speech acts: direct (when the structure of the utterance corresponds to the communicative intention) and indirect (when the speaker does not directly state the intended meaning of the utterance). The recognition of these acts was studied using written [134], spoken [135] or audiovisual [131, 136] modalities.

For instance, Egorova et al. [131] investigated the processing of the same noun in a context where the spoken word was used for two different and direct speech acts, either naming or requesting. EEG differences between the two speech acts occurred as 
soon as $120 \mathrm{~ms}$, and similar results were found also when naming and requesting were accompanied by gestures [136].

By using auditory materials, Gisladottir et al. [135] compared the ERPs during listening of the same target sentence I have a credit card that could convey three, more or less direct, speech acts depending on the prior context: the answer condition as the most direct speech act, e.g., How are you going to pay for the ticket?; a pre-offer, e.g., I don't have any money to pay for the ticket; and a declination, e.g., I can lend you money for the ticket. Differences between conditions concerned the beginning of the utterance and the onset of the critical word, but did not clearly involve a specific ERP component. Perhaps even more interesting were the results in Gisladottir et al. [137] in the time frequency domain: a power decrease for the lower bound of the beta range of the EEG was associated with declinations, as compared to answers and pre-offers, immediately preceding the target sentence.

Switching to indirect speech acts, Coulson and Lovett [134] compared the processing of the same utterance interpreted either as an indirect request or as a literal statement depending on the previous context: in a scenario where a married couple order a soup, the wife utters My soup is too cold to eat either to the waiter (indirect request) or to her husband (literal context). The analysis of slow cortical potentials revealed differences between conditions starting from the second word of the sentence [see also proverbs in 67], suggesting that the conversational context is taken early into account, even in absence of prosodic or gestural cues (in the written modality). Experimental work on other relevant aspects of conversation have been studied, although not extensively yet. One is the use of pregnant pause in conversation [138, 139], which may be associated with larger late positive effects in the ERPs due to the fact that "no" responses, usually preceding longer pauses, are disaffiliative and induce an evaluative process (in line with morally objectionable statements [106] or insults [110]).

Overall, the literature on the ERP correlates of conversation is very promising, although the effects do not easily map onto the traditional components of language processing, possibly because conversational processes themselves are less clearly timelocked to individual words (as in the obvious case of pauses [138]) and affected by multiple factors (sentence content, prosody, gestures). One thing that seems to emerge consistently is that some conversational mechanisms such as the recognition of speech acts can occur very early. These early effects indicate that pragmatic factors are quickly accounted for and allow for a smooth and fast transition between conversational turns. 


\section{ERP responses related to pragmatics in clinical conditions}

In this section we address an important yet poorly investigated topic, namely the EEG signature of impaired pragmatic processing. Pragmatic disorders can happen in a vast number of clinical populations, both neurological and psychiatric, affecting expressive as well as receptive skills [140]. In particular, there is EEG evidence of disrupted pragmatic processing in two of the domains described earlier, namely figurative language and discourse comprehension [141-144].

One of the conditions mostly affected by pragmatic impairment is schizophrenia, a mental illness characterized by a cohort of symptoms including cognitive [e.g., 145, 146] as well as linguistic deficits [e.g., 147, 148]. As one of the hallmarks of language disturbances in schizophrenia the literature documented the so-called 'concretism', namely a difficulty in abstract thinking and in the interpretation of non-literal meanings [149]. For instance, a patient asked to explain the meaning of "The lawyer is a shark" might reply that "It means that the lawyer swims fast". Behavioral reports of impaired figurative language processing are supported by a bunch of studies evidencing altered EEG processing of figurative language. In Strandburg et al. [150] participants were presented with idiomatic (dead beat), literal (vicious dog) and unrelated (square wind) word pairs during EEG recording. Whereas controls showed a graded N400 effect (Idiomatic $<$ Literal $<$ Unrelated), individuals with schizophrenia only showed a larger N400 for Unrelated vs Literal conditions, suggesting that they may not benefit of those contextual cues that allow for smoothly process figurative multi-word expressions. Two other studies on metaphor processing reported a reduced N400 in schizophrenia with respect to the control group. Importantly, however, the N400 reduction did not specifically affect the metaphoric condition, being present also for literal sentences $[151,152]$. A diminished sensitivity of the N400 to contextual expectations is a consolidated finding in the literature [for meta-analysis and a review see 153,154] and suggests that the most evident problem of language comprehension for individuals with schizophrenia is the difficulty of using contextual cues in processing discourse [e.g., 155, 156]. It is interesting to notice that also in the case of individuals with Asperger Syndrome there seems to be a reduced N400 sensitivity compared to neurotypical individuals. The study of Gold et al. [157] showed that individuals with Asperger Syndrome exhibited a marked N400 for novel metaphorical pairs (compared to literal metaphoric word pairs) that was on par with the N400 for unrelated word pairs (Conventional Metaphor $=$ Literal $<$ Unrelated $=$ Novel Metaphor $)$, a pattern that was different from the one observed for the control group (Conventional Metaphor $=$ Literal $=$ Novel Metaphor $<$ Unrelated).

Other evidence comes from studies on irony and the P600. Del Goleto et al. [158] found differences between two groups of participants with high or low schizotypy 
(i.e. schizophrenia-like personality traits), reporting that only the low schizotypal group showed the P600 effect to irony. Irony has been investigated also in relation to dysphoria, reporting mood-related alterations in the P600 [159]: specifically, in this study differences between the group with dysphoria and the control group concerned the spatial distribution of the P600.

Such a paucity of studies investigating pragmatic phenomena using EEG in the clinical domain raises the question as to whether EEG based indexes can be used as pathological biomarkers. In this respect, there is still a lot of work to do, extending investigation to other pathological conditions, and focusing on a larger set of indexes.

\section{Conclusions and future directions}

In this chapter we provided an extended overview of the electrophysiological correlates of language comprehension when it involves pragmatic processing. Across the domains of non-literal language, discourse and conversation we observed that two ERP components are engaged in the vast majority of the studies, namely the N400 and the P600. Pragmatic processes seem to be associated also with a set of long-lasting negativities, albeit these are less commonly observed. Figure 1 summarizes the main ERP effects for pragmatics.

The value of the accumulated evidence is twofold. On the one hand, the knowledge about the functional meaning of these components has been used to investigate key issues in pragmatics. On the other hand, the work reviewed here allows refining and extending the functional interpretation of the ERP components in general, which have rarely been described from a pragmatic perspective [3, 127, 160].

Starting with the first point, that is, the contribution of the ERP literature to solve pragmatic issues, one of the questions that mostly dominated the field of experimental pragmatics concerns whether the access to non-literal meaning is direct [161] or indirect [37]. ERP research offers important evidence to solve the debate on this issue, although the answer may not be straightforward. The observed reduction of the N400 size supports a rather direct access to figurative meaning in the case of idioms [59, 61], and metaphors, when they are conventional or when the context is supportive enough [44, 45, 52]. However, the larger N400 for novel metaphors [44, 45] and the fact that literal meanings can prime the figurative meaning of metaphors [55] suggest that more demanding processes related to the selection of the relevant conceptual properties of the "literal" vehicle are needed. Importantly, the study of irony and humor shows the involvement of the P600 component in non-literal interpretation [73, 81, 90], which points to a second - later - route for indirectness, more clearly linked to inferential processes. Similar effects are observed also in lexical pragmatics phenomena, especially when metaphors are embedded in sentences [49, 52]. Globally, the results speak of two distinct indirect routes, one touching the meaning of the words to be intended 
figuratively (N400), the other using inferences to derive an interpretation [52, 73], update [127], or integrate [13] the mental representation of the discourse (P600).

With respect to the contribution of the ERP literature on pragmatics to the ERP literature on language in general, this mainly involves the functional interpretation of both N400 and P600. The widely accepted relationship between N400 and retrieval from semantic memory [14] finds new and important support in the studies mentioned in this chapter. First, the N400 is sensitive to the relative degree of lexicalization of figurative expressions [45, 61], which is consistent with lexical frequency effects on single words [e.g., 162, 163]. Second, the N400 is dependent on contextual expectations also when processing figurative expressions [52, 59], as it is for processing literal language [14, 100]. Moreover, studies in pragmatics allow to extend the classic view on the N400, offering a unique perspective: for instance, if we further scrutinize the role of the N400 in metaphor, a growing body of evidence suggests that meaning selection may involve further processes, such as analogical mapping, in which mental images play a role, as suggested by work on concrete versus abstract metaphors [46, 164-166]. Concerning the role of the P600, it is now widely accepted that this component is not only related to syntax [12, 13, 127, 167]. Studies of mind-reading pragmatics are indicative of inferential mechanisms underlying the P600 [81] and similarly for lexical pragmatics phenomena the short-lived P600 effects may reflect the effort spent to infer the sentence interpretation [52] or to perform "minor" updates of the sentence interpretation [127]. Collectively, the evidence reviewed here greatly contributes to finetune the interpretation of the beyond-syntax P600, considering also a pragmatic perspective on the P600.

Our hope is that this chapter will encourage future research in both directions: using ERP components for investigating pragmatic mechanisms, and using pragmatic phenomena to elucidate the nature of ERP effects. When planning future research, a number of further questions appear as outstanding and should receive primary attention:

\section{1) The definition of the entire set of ERP components associated with pragmatic} processing. The cognitive mechanisms involved in pragmatic phenomena do not only impact the N400 and P600 (see Figure 1). As illustrated in the sections above, long lasting ERP effects with a negative polarity have been observed for ambiguous anaphors (the Nref [123]), for the processing of literary metaphors (sustained negativity [51]), or for humor processing (sustained LAN [84, 88]). We may argue that all these linguistic phenomena are linked to the additional search for information in the mental representation of the discourse, needed to choose the right referent for an ambiguous anaphor, to indulge in deriving an array of weak implicatures in poetry, or to search for a solution cracking the joke. However, it is not trivial to determine whether the three negative effects are due to the same or different processing mechanisms, because they show different scalp distributions (more or less lateralized, although mainly with a frontal focus). Moreover, the literature features several positive ERP effects that 

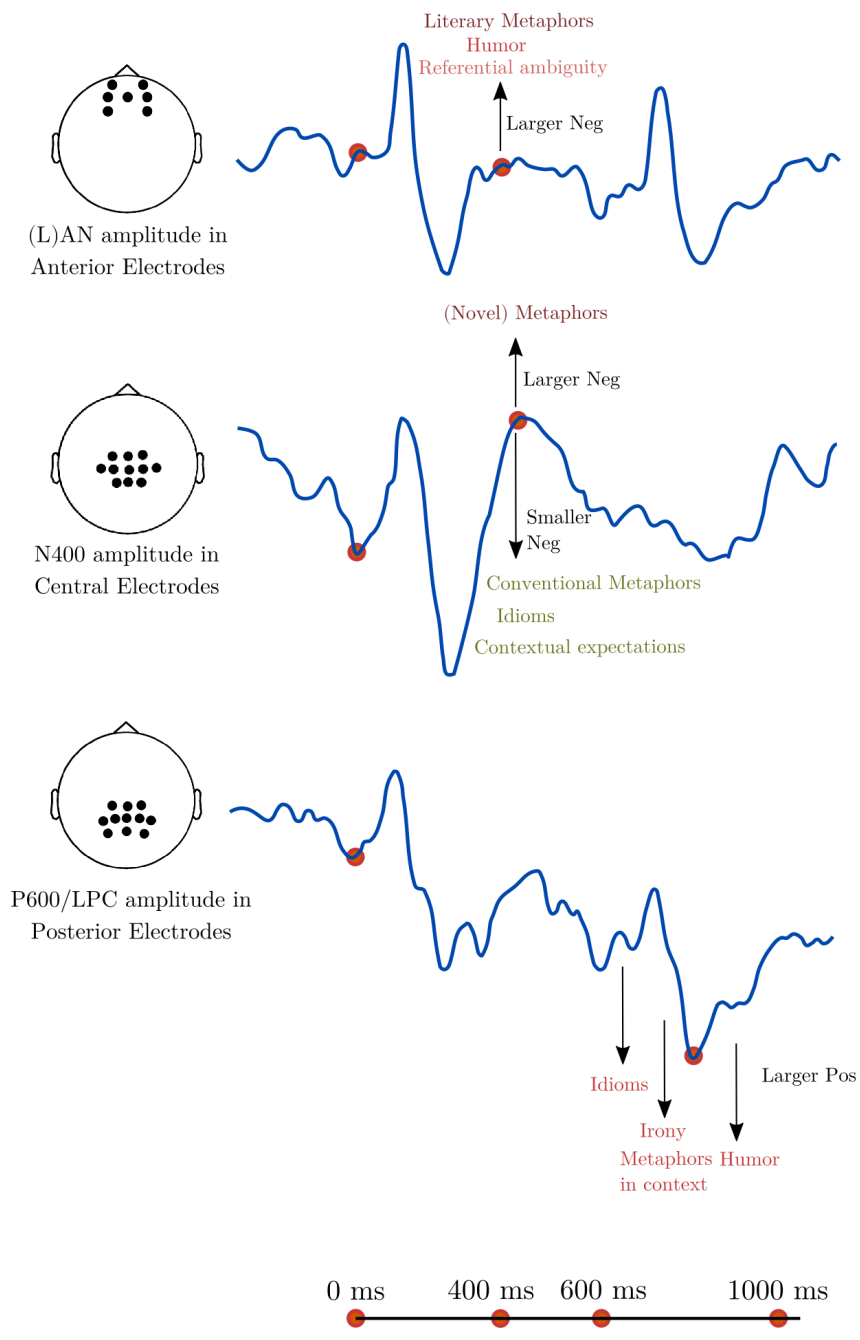

Figure 1: ERP components in pragmatics - The figure displays the relation between the range of pragmatic phenomena described in the Chapter and the ERP components. Negativity is plotted upwards, and reference to temporal and topographic information is provided on the time scale at the bottom, and on the head models on the left. The position where the name of the different penomena is printed depends on the typical latency and direction (larger or smaller amplitude of each component) of the ERP effects observed in the literature. The top row shows an ERP waveform recorded from Anterior electrodes where anterior negativities are typically found for literary metaphor, humor and referential ambiguity (we refer collectively to Left Anterior Negativity, Sustained Anterior Negativity, and Nref). The second row shows an ERP waveform recorded from Central electrodes where the N400 typically occurs for metaphors (novel and conventional), idioms and contextual expectations. The third row shows an ERP waveform from Posterior electrodes where P600 and LPC are typically found for idioms, irony, metaphor in context, and humor. 
are often interpreted referring to the LPC component, but a shared definition of its functional role in pragmatics is still missing. For instance, the association of LPC and the processing of jokes suggests that the underlying mechanisms may involve an elaborative and evaluative processing stage, on par with evidence from the study of insults and moral transgressions in which ERP differences affect the LPP [106, 109, 110]. Yet it is unclear how to distinguish between the LPC and the P600 components, or whether it is possible to determine a canonical timing or scalp distribution for the pragmatic P600 at all. Finally, the early (i.e., before the N400) response observed for instance in the case of speech acts $[131,136]$ points to the idea that the inventory of pragmatics-related ERP components could include also early effects, possibly linked to fast and automatic conversational mechanisms: this is certainly a domain where more testing is needed.

2) The role of individual differences on pragmatics-related ERP effects. The interest in the study of individual differences to better describe language processing mechanisms has characterized research on language comprehension from its infancy, focusing on aspects such as memory [e.g., 168] and age [e.g., 169]. Notably, the evidence reviewed in this chapter shows that many individual factors may have an impact on the ERPs associated with pragmatic phenomena, including cognitive skills in the case of metaphor [47], specific knowledge about a story [104], but also moral values [106], gender beliefs [116], and social skills in the case of humor [88] and scalars [170]. The inclusion of individual factors in the ERP analysis is, however, sporadic. A proper pragmatic framework should pay considerably more attention to individual variability, as these extralinguistic factors are an important part of a broad notion of context, as intended in pragmatics.

3) The functional meaning of EEG oscillations. Concerning the time-frequency domain of the EEG in pragmatics, studies are very few and the results are not always consistent. The roles of power drops in the beta and in the gamma ranges seem of particular interest, since the former may be a consequence of major revision processes [88] and the latter may be associated with the idling of semantic composition mechanisms [59, 63] in favor of more pragmatic processes. Given the importance of oscillations to fully understand language processing [22, 24, 171], it is key that future studies in pragmatics more systematically include the exploration of the time frequency domain of the EEG for favoring an integrated account of language comprehension, extending beyond syntax and semantics.

Probably, answers to these open issues will come also from the study of a larger set of pragmatic phenomena than the selection considered in this chapter. Here we have focused on non-literal language and discourse and conversation, both because they are 
theoretically salient in pragmatics and because they have been extensively studied with the EEG based measures. However, pragmatic mechanisms are involved also in several other language phenomena, on which electrophysiological investigation is still scarce. A non-exhaustive list includes the processing of scalars [170, 172, 173], negation [174, 175] lies [176], and those phenomena at the interface with discourse factors, such as the questions under discussion (QUD) [177], or the interaction between prosody and information structure [178]. 


\section{Author Contribution}

VB conceived the structure of the chapter and the pragmatic framework presented in 1.1; both authors contributed to retrieve and interpret the content of the different sections; PC wrote the first draft of the manuscript; VB revised the text.

\section{Conflict of interest}

The authors declare that they have no conflict of interest.

\section{References}

[1] Kutas, M., \& Van Petten, C. (1994). Psycholinguistics Electrified: Eventrelated potential investigations. In M. A. Gernsbacher (Ed.), Handbook of Psycholinguistics (pp. 83-143). Cambridge, Massachusetts, Academic Press.

[2] Kutas, M., Van Petten, C., \& Kluender, R. (2006). Psycholinguistics Electrified II: 1994-2005. In M. J. Traxler \& M. A. Gernsbacher (Eds.), Handbook of Psycholinguistics, 2nd Edition (pp. 659-724). New York, Elsevier.

[3] Van Berkum, J. J. (2009). The neuropragmatics of 'simple' utterance comprehension: An ERP review. In U. Breheny R Sauerland \& K. Yatsushiro (Eds.), Semantics and pragmatics: From experiment to theory (pp. 276-316). Basingstoke, Palgrave Macmillan.

[4] Levinson, S. C. (1983). Pragmatics. Cambridge, Cambridge University Press. https://doi.org/10.1017/CBO9780511813313

[5] Bar-Hillel, M. (1971). Pragmatics of Natural Languages. Netherlands, Springer. https://doi.org/10.1007/9789401017138

[6] Mey, J. (1998). Pragmatics. In J. Mey (Ed.), Concise Encyclopedia of Pragmatics (pp. 716-737). Amsterdam, Elsevier.

[7] Verschueren, J., \& Verschueren, J. (1999). Understanding Pragmatics. London, Arnold. https://books.google.it/books?id=pOsU-xSlhBwC

[8] Sperber, D., \& Wilson, D. (2005). Pragmatics. In F. Jackson \& M. Smith (Eds.), The Oxford Handbook of Contemporary Philosophy (pp. 468-503). Oxford, Oxford University Press.

[9] Horn, L. R., \& Ward, G. (1999). Pragmatics. In R. A. Wilson \& F. C. Keil (Eds.), The MIT Encyclopedia of the Cognitive Sciences (pp. 661-664). MA, MIT Press.

[10] Allott, N. (2010). Key Terms in Pragmatics. London, Bloomsbury Academic. https://books.google.it/books?id=qLkMbIiLG1AC 
[11] Luck, S. J., \& Kappenman, E. S. (2011). The Oxford Handbook of Event-Related Potential Components. Oxford, Oxford University Press. https://doi.org/10. 1093/oxfordhb/9780195374148.001.0001

[12] Kuperberg, G. R. (2007). Neural mechanisms of language comprehension: Challenges to syntax. Brain Research, 1146, 23-49. https://doi.org/10.1016/j. brainres.2006.12.063

[13] Brouwer, H., \& Hoeks, J. C. (2013). A time and place for language comprehension: mapping the $\mathrm{N} 400$ and the P600 to a minimal cortical network. Frontiers in Human Neuroscience, 7, 758. https : //doi.org/10.3389/fnhum.2013.00758

[14] Kutas, M., \& Federmeier, K. D. (2011). Thirty years and counting: finding meaning in the N400 component of the event-related brain potential (ERP). Annual Review of Psychology, 62(1), 621-647. https://doi.org/10.1146/annurev. psych.093008.131123

[15] Lau, E. F., Phillips, C., \& Poeppel, D. (2008). A cortical network for semantics:(de) constructing the N400. Nature Reviews Neuroscience, 9(12), 920-933. https://doi.org/10.1038/nrn2532

[16] Osterhout, L., \& Holcomb, P. J. (1992). Event-related brain potentials elicited by syntactic anomaly. Journal of Memory and Language, 31(6), 785-806. https: //doi.org/10.1016/0749-596X(92)90039-Z

[17] Kolk, H., \& Chwilla, D. (2007). Late positivities in unusual situations. Brain and Language, 100(3), 257-261. https://doi.org/10.1016/j.bandl.2006.07.006

[18] Kuperberg, G. R., Sitnikova, T., Caplan, D., \& Holcomb, P. J. (2003). Electrophysiological distinctions in processing conceptual relationships within simple sentences. Brain Research. Cognitive Brain Research, 17(1), 117-29. https://doi.org/10.1016/S0926-6410(03)00086-7

[19] Kim, A., \& Osterhout, L. (2005). The independence of combinatory semantic processing: Evidence from event-related potentials. Journal of Memory and Language, 52(2), 205-225. https://doi.org/10.1016/j.jml.2004.10.002

[20] Van Petten, C., \& Luka, B. J. (2012). Prediction during language comprehension: Benefits, costs, and ERP components. International Journal of Psychophysiology, 83(2), 176-190. https://doi.org/10.1016/j.ijpsycho.2011.09. 015

[21] Pynte, J., Besson, M., Robichon, F.-H., \& Poli, J. (1996). The time-course of metaphor comprehension: An event-related potential study. Brain and Language, 55(3), 293-316. https://doi.org/10.1006/brln.1996.0107

[22] Bastiaansen, M., Mazaheri, A., \& Jensen, O. (2012). Beyond ERPs: oscillatory neuronal dynamics. In S. Luck \& E. Kappenman (Eds.), Oxford Handbook of Event-Related Potential Components (pp. 31-49). Oxford, Oxford University Press. 
[23] Lewis, A. G., Wang, L., \& Bastiaansen, M. (2015). Fast oscillatory dynamics during language comprehension: Unification versus maintenance and prediction? Brain and Language, 148, 51-63. https://doi.org/10.1016/j.bandl. 2015.01.003

[24] Meyer, L. (2018). The neural oscillations of speech processing and language comprehension: state of the art and emerging mechanisms. European Journal of Neuroscience, 48(7), 2609-2621. https://doi.org/10.1111/ejn.13748

[25] Prystauka, Y., \& Lewis, A. G. (2019). The power of neural oscillations to inform sentence comprehension: A linguistic perspective. Language and Linguistics Compass, 13(9), e12347. https://doi.org/10.1111/lnc3.12347

[26] Weiss, S., \& Mueller, H. M. (2012). "Too many betas do not spoil the broth": the role of beta brain oscillations in language processing. Frontiers in Psychology, 3, 201. https://doi.org/10.3389/fpsyg.2012.00201

[27] Giraud, A.-L., \& Poeppel, D. (2012). Cortical oscillations and speech processing: emerging computational principles and operations. Nature Neuroscience, 15(4), 511-517. https://doi.org/10.1038/nn.3063

[28] Nunberg, G., Sag, I. A., \& Wasow, T. (1994). Idioms. Language, 70(3), 491538. https://doi.org/10.1353/lan.1994.0007

[29] Libben, M. R., \& Titone, D. A. (2008). The multidetermined nature of idiom processing. Memory \& Cognition, 36(6), 1103-1121. https://doi.org/10.3758/ MC.36.6.1103

[30] Gibbs, R. W. (2001). Proverbial themes we live by. Poetics, 29(3), 167-188. https://doi.org/10.1016/S0304-422X(01)00041-9

[31] Glucksberg, S. (2003). The psycholinguistics of metaphor. Trends in Cognitive Sciences, 7(2), 92-96. https://doi.org/10.1016/S1364-6613(02)00040-2

[32] Carston, R. (2012). Metaphor and the literal/non-literal distinction. In K. Allan \& K. M. Jaszczolt (Eds.), The Cambridge Handbook of Pragmatics (pp. 469-492). Cambridge, Cambridge University Press. https://doi.org/10.1017/CBO9781139022453.025

[33] Bowdle, B. F., \& Gentner, D. (2005). The career of metaphor. Psychological Review, 112(1), 193-216. https://doi.org/10.1037/0033-295X.112.1.193

[34] Carston, R. (2010). Lexical pragmatics, ad hoc concepts and metaphor: from a relevance theory perspective. Italian Journal of Linguistics, 22(1), 153-180. http://linguistica.sns.it/RdL/22.1/carston.pdf

[35] Wilson, D. (2003). Relevance and lexical pragmatics. Italian Journal of Linguistics, 15, 273-292. http://www. italian - journal - linguistics.com/wp content/uploads/03.Wilson.pdf

[36] Wilson, D., \& Carston, R. (2007). A unitary approach to lexical pragmatics: Relevance, inference and ad hoc concepts. In N. Burton-Roberts (Ed.), Pragmatics (pp. 230-259). Basingstoke, Palgrave-Macmillan. 
https://www.researchgate.net/publication/239542817_A_Unitary_Approach_ to_Lexical_Pragmatics_Relevance_Inference_and_Ad_Hoc_Concepts

[37] Grice, H. P. (1975). Logic and Conversation. Leiden, The Netherlands, Brill. https://doi.org/10.1163/9789004368811_003

[38] Wilson, D., \& Sperber, D. (1992). On verbal irony. Lingua, 87(1), 53-76. https: //doi.org/10.1016/0024-3841(92)90025-E

[39] Attardo, S. (1994). Linguistic Theories of Humor. Berlin, Boston, De Gruyter Mouton. https://doi.org/10.1515/9783110219029

[40] Arzouan, Y., Goldstein, A., \& Faust, M. (2007). Brainwaves are stethoscopes: ERP correlates of novel metaphor comprehension. Brain Research, 1160, 6981. https://doi.org/10.1016/j.brainres.2007.05.034

[41] Bonnaud, V., Gil, R., \& Ingrand, P. (2002). Metaphorical and non-metaphorical links: a behavioral and ERP study in young and elderly adults. Neurophysiologie Clinique/Clinical Neurophysiology, 32(4), 258-268. https://doi.org/10.1016/ S0987-7053(02)00307-6

[42] Forgács, B., Bardolph, M. D., Amsel, B. D., DeLong, K. A., \& Kutas, M. (2015). Metaphors are physical and abstract: ERPs to metaphorically modified nouns resemble ERPs to abstract language. Frontiers in Human Neuroscience, 9, 28. https://doi.org/10.3389/fnhum.2015.00028

[43] Forgács, B. (2020). An Electrophysiological Abstractness Effect for Metaphorical Meaning Making. Eneuro. https://doi.org/10.1523/ENEURO. 0052-20.2020

[44] Goldstein, A., Arzouan, Y., \& Faust, M. (2012). Killing a novel metaphor and reviving a dead one: ERP correlates of metaphor conventionalization. Brain and Language, 123(2), 137-142. https://doi.org/10.1016/j.bandl.2012.09.008

[45] Lai, V. T., Curran, T., \& Menn, L. (2009). Comprehending conventional and novel metaphors: An ERP study. Brain Research, 1284, 145-155. https://doi. org/10.1016/j.brainres.2009.05.088

[46] Lai, V. T., \& Curran, T. (2013). ERP evidence for conceptual mappings and comparison processes during the comprehension of conventional and novel metaphors. Brain and Language, 127(3), 484-496. https : //doi.org/10.1016/j.bandl.2013.09.010

[47] Kazmerski, V. A., Blasko, D. G., \& Dessalegn, B. G. (2003). ERP and behavioral evidence of individual differences in metaphor comprehension. Memory \& Cognition, 31(5), 673-689. https://doi.org/10.3758/BF03196107

[48] Tartter, V. C., Gomes, H., Dubrovsky, B., Molholm, S., \& Stewart, R. V. (2002). Novel metaphors appear anomalous at least momentarily: Evidence from N400. Brain and Language, 80(3), 488-509. https://doi.org/10.1006/brln.2001.2610

[49] De Grauwe, S., Swain, A., Holcomb, P. J., Ditman, T., \& Kuperberg, G. R. (2010). Electrophysiological insights into the processing of 
nominal metaphors. Neuropsychologia, 48(7), 1965-1984. https //doi.org/10.1016/j.neuropsychologia.2010.03.017

[50] Fondevila, S., Aristei, S., Sommer, W., Jiménez-Ortega, L., Casado, P., \& Martın-Loeches, M. (2016). Counterintuitive Religious Ideas and Metaphoric Thinking: An Event-Related Brain Potential Study. Cognitive Science, 40(4), 972-991. https://doi.org/10.1111/cogs.12263

[51] Bambini, V., Canal, P., Resta, D., \& Grimaldi, M. (2019). Time course and neurophysiological underpinnings of metaphor in literary context. Discourse Processes, 56(1), 77-97. https://doi.org/10.1080/0163853X.2017.1401876

[52] Bambini, V., Bertini, C., Schaeken, W., Stella, A., \& Di Russo, F. (2016). Disentangling metaphor from context: an ERP study. Frontiers in Psychology, 7, 559. https://doi.org/10.3389/fpsyg.2016.00559

[53] Coulson, S., \& Van Petten, C. (2002). Conceptual integration and metaphor: An event-related potential study. Memory \& Cognition, 30(6), 958-968. https: //doi.org/10.3758/BF03195780

[54] Schmidt-Snoek, G. L., Drew, A. R., Barile, E. C., \& Agauas, S. J. (2015). Auditory and motion metaphors have different scalp distributions: an ERP study. Frontiers in Human Neuroscience, 9, 126. https : //doi.org/10.3389/fnhum.2015.00126

[55] Weiland, H., Bambini, V., \& Schumacher, P. B. (2014). The role of literal meaning in figurative language comprehension: Evidence from masked priming ERP. Frontiers in Human Neuroscience, 8, 583. https://doi.org/10.3389/fnhum.2014.00583

[56] Rataj, K., Przekoracka-Krawczyk, A., \& Van der Lubbe, R. H. (2018). On understanding creative language: the late positive complex and novel metaphor comprehension. Brain Research, 1678, 231-244. https://doi.org/10.1016/j.brainres.2017.10.030

[57] Rutter, B., Kröger, S., Hill, H., Windmann, S., Hermann, C., \& Abraham, A. (2012). Can clouds dance? Part 2: An ERP investigation of passive conceptual expansion. Brain and Cognition, 80(3), 301-310. https://doi. org/10.1016/j. bandc.2012.08.003

[58] Tang, X., Qi, S., Wang, B., Jia, X., \& Ren, W. (2017). The temporal dynamics underlying the comprehension of scientific metaphors and poetic metaphors. Brain Research, 1655, 33-40. https://doi.org/10.1016/j.brainres.2016.11.005

[59] Canal, P., Pesciarelli, F., Vespignani, F., Molinaro, N., \& Cacciari, C. (2017). Basic composition and enriched integration in idiom processing: An EEG study. Journal of Experimental Psychology: Learning, Memory, and Cognition, 43(6), 928-943. https://doi.org/10.1037/xlm0000351 
[60] Moreno, E. M., Federmeier, K. D., \& Kutas, M. (2002). Switching languages, switching palabras (words): An electrophysiological study of code switching. Brain and Language, 80(2), 188-207. https://doi.org/10.1006/brln.2001.2588

[61] Vespignani, F., Canal, P., Molinaro, N., Fonda, S., \& Cacciari, C. (2010). Predictive mechanisms in idiom comprehension. Journal of Cognitive Neuroscience, 22(8), 1682-1700. https://doi.org/10.1162/jocn.2009.21293

[62] Molinaro, N., \& Carreiras, M. (2010). Electrophysiological evidence of interaction between contextual expectation and semantic integration during the processing of collocations. Biological Psychology, 83(3), 176-190. https://doi.org/10.1016/j.biopsycho.2009.12.006

[63] Rommers, J., Dijkstra, T., \& Bastiaansen, M. (2013). Context-dependent semantic processing in the human brain: Evidence from idiom comprehension. Journal of Cognitive Neuroscience, 25(5), 762-776. https://doi.org/10.1162/jocn_a_00337

[64] Federmeier, K. D., \& Kutas, M. (1999). A rose by any other name: Long-term memory structure and sentence processing. Journal of Memory and Language, 41(4), 469-495. https://doi.org/10.1006/jmla.1999.2660

[65] Bianchi, B., Shalom, D. E., \& Kamienkowski, J. E. (2019). Predicting Known Sentences: Neural Basis of Proverb Reading Using Non-parametric Statistical Testing and Mixed-Effects Models. Frontiers in Human Neuroscience, 13, 82. https://doi.org/10.3389/fnhum.2019.00082

[66] Cermolacce, M., Scannella, S., Faugère, M., Vion-Dury, J., \& Besson, M. (2014). "All that glitters is not..." alone. Congruity effects in highly and less predictable sentence contexts. Neurophysiologie Clinique/Clinical Neurophysiology, 44(2), 189-201. https://doi.org/10.1016/j.neucli.2014.04.001

[67] Ferretti, T. R., Schwint, C. A., \& Katz, A. N. (2007). Electrophysiological and behavioral measures of the influence of literal and figurative contextual constraints on proverb comprehension. Brain and Language, 101(1), 38-49. https://doi.org/10.1016/j.bandl.2006.07.002

[68] Ferretti, T. R., Katz, A. N., Schwint, C. A., Patterson, C., \& Pradzynski, D. (2020). How discourse constraints influence neurolinguistic mechanisms during the comprehension of proverbs. Cognitive, Affective, \& Behavioral Neuroscience, 20, 604-623. https://doi.org/10.3758/s13415-020-00790-9

[69] Ferretti, T. R., Hall, D. C., \& Mansour, F. (2020). Interpreting pragmatic markers following proverbs. Canadian journal of experimental psychology/Revue canadienne de psychologie experimentale. https://doi.org/10.1037/cep0000231

[70] Schumacher, P. B. (2011). The hepatitis called ... Electrophysiological evidence for enriched composition. In J. Meibauer \& M. Steinbach (Eds.), Experimental Pragmatics/semantics (pp. 199-219). Amsterdam/Philadelphia, 
John Benjamins Publishing Company. https:// books.google.it/books ? id = Puw0aPVU1AoC

[71] Schumacher, P. B. (2014). Content and context in incremental processing: "the ham sandwich" revisited. Philosophical Studies, 168(1), 151-165. https://doi. org/10.1007/s11098-013-0179-6

[72] Regel, S., Coulson, S., \& Gunter, T. C. (2010). The communicative style of a speaker can affect language comprehension? ERP evidence from the comprehension of irony. Brain Research, 1311, 121-135. https://doi.org/10.1016/j.brainres.2009.10.077

[73] Regel, S., Gunter, T. C., \& Friederici, A. D. (2011). Isn't it ironic? An electrophysiological exploration of figurative language processing. Journal of Cognitive Neuroscience, 23(2), 277-293. https://doi.org/10.1162/jocn.2010. 21411

[74] Regel, S., Meyer, L., \& Gunter, T. C. (2014). Distinguishing neurocognitive processes reflected by P600 effects: Evidence from ERPs and neural oscillations. PLOS ONE, 9(5), 1-11. https://doi.org/10.1371/journal.pone. 0096840

[75] Regel, S., \& Gunter, T. C. (2017). Don't get me wrong: ERP evidence from cueing communicative intentions. Frontiers in Psychology, 8, 1465. https://doi. org/10.3389/fpsyg.2017.01465

[76] Gibson, L., Atchley, R. A., Voyer, D., Diener, U. S., \& Gregersen, S. (2016). Detection of sarcastic speech: The role of the right hemisphere in ambiguity resolution. Laterality, 21(4-6), 549-567. https://doi .org/10.1080/1357650X. 2015.1105246

[77] Wickens, S., \& Perry, C. (2015). What do you mean by that?! An electrophysiological study of emotional and attitudinal prosody. PLOS ONE, 10(7), 1-24. https://doi.org/10.1371/journal.pone.0132947

[78] Caffarra, S., Michell, E., \& Martin, C. D. (2018). The impact of foreign accent on irony interpretation. PLOS ONE, 13(8), 1-13. https:// doi .org/10.1371/ journal.pone.0200939

[79] Filik, R., Leuthold, H., Wallington, K., \& Page, J. (2014). Testing theories of irony processing using eye-tracking and ERPs. Journal of Experimental Psychology: Learning, Memory, and Cognition, 40(3), 811-828. https://doi.org/10.1037/a0035658

[80] Weissman, B., \& Tanner, D. (2018). A strong wink between verbal and emoji-based irony: How the brain processes ironic emojis during language comprehension. PLOS ONE, 13(8), 1-26. https://doi.org/10.1371/journal.pone. 0201727 
[81] Spotorno, N., Cheylus, A., Van Der Henst, J.-B., \& Noveck, I. A. (2013). What's behind a P600? Integration operations during irony processing. PLOS ONE, 8(6), 1-10. https://doi.org/10.1371/journal.pone.0066839

[82] Baptista, N. I., Manfredi, M., \& Boggio, P. S. (2018). Medial prefrontal cortex stimulation modulates irony processing as indexed by the N400. Social Neuroscience, 13(4), 495-510. https :// doi . org/10 . 1080/17470919.2017. 1356744

[83] Caillies, S., Gobin, P., Obert, A., Terrien, S., Coutté, A., Iakimova, G., \& Besche-Richard, C. (2019). Asymmetry of affect in verbal irony understanding: What about the N400 and P600 components? Journal of Neurolinguistics, 51, 268-277. https://doi.org/10.1016/j.jneuroling.2019.04.004

[84] Coulson, S., \& Kutas, M. (2001). Getting it: human event-related brain response to jokes in good and poor comprehenders. Neuroscience Letters, 316(2), 71-74. https://doi.org/10.1016/S0304-3940(01)02387-4

[85] Coulson, S., \& Williams, R. F. (2005). Hemispheric asymmetries and joke comprehension. Neuropsychologia, 43(1), 128-41. https : //doi.org/10.1016/j.neuropsychologia.2004.03.015

[86] Feng, Y.-J., Chan, Y.-C., \& Chen, H.-C. (2014). Specialization of neural mechanisms underlying the three-stage model in humor processing: An ERP study. Journal of Neurolinguistics, 32, 59-70. https://doi.org/10.1016/j.jneuroling.2014.08.007

[87] Mayerhofer, B., \& Schacht, A. (2015). From incoherence to mirth: neurocognitive processing of garden-path jokes. Frontiers in Psychology, 6, 550. https://doi.org/10.3389/fpsyg.2015.00550

[88] Canal, P., Bischetti, L., Di Paola, S., Bertini, C., Ricci, I., \& Bambini, V. (2019). 'Honey, shall I change the baby? - Well done, choose another one': ERP and time-frequency correlates of humor processing. Brain and Cognition, 132, 4155. https://doi.org/10.1016/j.bandc.2019.02.001

[89] Coulson, S., \& Lovett, C. (2004). Handedness, hemispheric asymmetries, and joke comprehension. Cognitive Brain Research, 19(3), 275-288. https://doi.org/ 10.1016/j.cogbrainres.2003.11.015

[90] Marinkovic, K., Baldwin, S., Courtney, M. G., Witzel, T., Dale, A. M., \& Halgren, E. (2011). Right hemisphere has the last laugh: neural dynamics of joke appreciation. Cognitive, Affective, \& Behavioral Neuroscience, 11(1), 113-130. https://doi.org/10.3758/s13415-010-0017-7

[91] Wang, R. W., Kuo, H.-C., \& Chuang, S.-W. (2017). Humor drawings evoked temporal and spectral EEG processes. Social Cognitive and Affective Neuroscience, 12(8), https://academic.oup.com/scan/articlepdf/12/8/1359/27104696/nsx054.pdf, 1359-1376. https://doi.org/10.1093/scan/ nsx054 
[92] Perchtold-Stefan, C. M., Papousek, I., Rominger, C., Schertler, M., Weiss, E. M., \& Fink, A. (2020). Humor comprehension and creative cognition: Shared and distinct neurocognitive mechanisms as indicated by EEG alpha activity. NeuroImage, 213, 116695. https://doi.org/10.1016/j.neuroimage.2020.116695

[93] Molinaro, N., Barber, H. A., \& Carreiras, M. (2011). Grammatical agreement processing in reading: ERP findings and future directions. Cortex, 47(8), 908930. https://doi.org/10.1016/j.cortex.2011.02.019

[94] Suls, J. M. (1972). A two-stage model for the appreciation of jokes and cartoons: An information-processing analysis. In J. Goldstein \& P. Mcghee (Eds.), The Psychology of Humor; Theoretical Perspectives and Empirical Issues (pp. 81100). Cambridge, Massachusetts, Academic Press.

[95] Wyer, R. S., \& Collins, J. E. (1992). A theory of humor elicitation. Psychological review, 99(4), 663-688. https :// doi .org/10 . 1037 / 0033 295X.99.4.663

[96] Morton, J. (1969). Interaction of information in word recognition. Psychological Review, 76(2), 165-178. https://doi.org/10.1037/h0027366

[97] Swinney, D. A. (1979). Lexical access during sentence comprehension: (Re)consideration of context effects. Journal of verbal learning and verbal behavior, 18(6), 645-659. https://doi.org/10.1016/S0022-5371(79)90355-4

[98] Kutas, M., \& Hillyard, S. A. (1980). Reading senseless sentences: Brain potentials reflect semantic incongruity. Science, 207(4427), 203-205. https://doi.org/10.1126/science.7350657

[99] Taylor, W. L. (1953). "Cloze Procedure": A New Tool for Measuring Readability. Journalism Quarterly, 30(4), 415-433. https://doi.org/10.1177/ 107769905303000401

[100] Hagoort, P., \& Van Berkum, J. J. A. (2007). Beyond the sentence given. Philosophical Transactions of the Royal Society B: Biological Sciences, 362(1481), 801-811. https://doi.org/10.1098/rstb.2007.2089

[101] Van Berkum, J. J. A., van den Brink, D., Tesink, C. M. J. Y., Kos, M., \& Hagoort, P. (2008). The neural integration of speaker and message. Journal of Cognitive Neuroscience, 20(4), 580-591. https://doi.org/10.1162/jocn.2008.20054

[102] White, K. R., Crites, J., Stephen L., Taylor, J. H., \& Corral, G. (2009). Wait, what? Assessing stereotype incongruities using the N400 ERP component. Social Cognitive and Affective Neuroscience, 4(2), 191-198. https://doi.org/10.1093/scan/nsp004

[103] Hagoort, P., Hald, L., Bastiaansen, M., \& Petersson, K. M. (2004). Integration of word meaning and world knowledge in language comprehension, 304(5669), 438-441. https://doi.org/10.1126/science.1095455

[104] Troyer, M., \& Kutas, M. (2020). Harry Potter and the Chamber of What?: the impact of what individuals know on word processing during 
reading. Language, Cognition and Neuroscience, 35(5), 641-657. https://doi.org/10.1080/23273798.2018.1503309

[105] Nieuwland, M. S., \& Van Berkum, J. J. A. (2006a). When peanuts fall in love: N400 evidence for the power of discourse. Journal of Cognitive Neuroscience, 18(7), 1098-1111. https://doi.org/10.1162/jocn.2006.18.7.1098

[106] Van Berkum, J. J. A., Holleman, B., Nieuwland, M., Otten, M., \& Murre, J. (2009). Right or wrong? The brain's fast response to morally objectionable statements. Psychological Science, 20(9), 1092-1099. https://doi.org/10.1111/ j.1467-9280.2009.02411.x

[107] Foucart, A., Moreno, E. M., Martin, C. D., \& Costa, A. (2015). Integration of moral values during L2 sentence processing. Acta Psychologica, 162, 1-12. https://doi.org/10.1016/j.actpsy.2015.09.009

[108] Hundrieser, M., \& Stahl, J. (2016). How attitude strength and information influence moral decision making: Evidence from event-related potentials. Psychophysiology, 53(5), 678-688. https://doi.org/10.1111/psyp.12599

[109] Lu, J., Peng, X., Liao, C., \& Cui, F. (2019). The stereotype of professional roles influences neural responses to moral transgressions: ERP evidence. Biological Psychology, 145, 55-61. https://doi.org/10.1016/j.biopsycho.2019.04.007

[110] Otten, M., Mann, L., Van Berkum, J. J. A., \& Jonas, K. J. (2017). No laughing matter: How the presence of laughing witnesses changes the perception of insults. Social Neuroscience, 12(2), 182-193. https : //doi.org/10.1080/17470919.2016.1162194

[111] Wang, L., Zhu, Z., \& Bastiaansen, M. (2012). Integration or predictability? A further specification of the functional role of gamma oscillations in language comprehension. Frontiers in psychology, 3, 187. https://doi.org/10.3389/fpsyg. 2012.00187

[112] Hald, L. A., Bastiaansen, M. C., \& Hagoort, P. (2006). EEG theta and gamma responses to semantic violations in online sentence processing. Brain and Language, 96(1), 90-105. https://doi.org/10.1016/j.bandl.2005.06.007

[113] Metzner, P., von der Malsburg, T., Vasishth, S., \& Rösler, F. (2015). Brain responses to world knowledge violations: a comparison of stimulus- and fixation-triggered event-related potentials and neural oscillations. Journal of Cognitive Neuroscience, 27(5), 1017-1028. https://doi.org/10.1162/jocn_a_00731

[114] van Dijk, T., \& Kintsch, W. (1983). Strategies of Discourse Comprehension. Academic Press. https://books.google.it/books?id=X-JsAAAAIAAJ

[115] Callahan, S. M. (2008). Processing anaphoric constructions: Insights from electrophysiological studies. Journal of Neurolinguistics, 21(3), 231-266. https://doi.org/10.1016/j.jneuroling.2007.10.002 
[116] Canal, P., Garnham, A., \& Oakhill, J. (2015). Beyond gender stereotypes in language comprehension: Self sex-role descriptions affect the brain's potentials associated with agreement processing. Frontiers in Psychology, 6, 1953. https: //doi.org/10.3389/fpsyg.2015.01953

[117] Osterhout, L., Bersick, M., \& McLaughlin, J. (1997). Brain potentials reflect violations of gender stereotypes. Memory \& Cognition, 25(3), 273-285. https: //doi.org/10.3758/BF03211283

[118] Osterhout, L., \& Mobley, L. A. (1995). Event-related brain potentials elicited by failure to agree. Journal of Memory and Language, 34(6), 739-773. https: //doi.org/10.1006/jmla.1995.1033

[119] Swaab, T. Y., Camblin, C. C., \& Gordon, P. C. (2004). Electrophysiological evidence for reversed lexical repetition effects in language processing. Journal of Cognitive Neuroscience, 16(5), 715-726. https://doi.org/10.1162/ 089892904970744

[120] Nieuwland, M. S., \& Van Berkum, J. J. A. (2006b). Individual differences and contextual bias in pronoun resolution: Evidence from ERPs. Brain Research, 1118(1), 155-167. https://doi.org/10.1016/j.brainres.2006.08.022

[121] Van Berkum, J. J. A., Brown, C. M., \& Hagoort, P. (1999). Early referential context effects in sentence processing: Evidence from event-related brain potentials. Journal of Memory and Language, 41(2), 147-182.

[122] Van Berkum, J. J. A., Brown, C. M., Hagoort, P., \& Zwitserlood, P. (2003). Event-related brain potentials reflect discourse-referential ambiguity in spoken language comprehension. Psychophysiology, 40(2), 235-248. https://doi.org/ 10.1111/1469-8986.00025

[123] Van Berkum, J. J. A., Koornneef, A. W., Otten, M., \& Nieuwland, M. S. (2007). Establishing reference in language comprehension: An electrophysiological perspective [Mysteries of Meaning]. Brain Research, 1146, 158-171. https://doi.org/10.1016/j.brainres.2006.06.091

[124] Nieuwland, M. S. (2014). "Who's he?" Event-related brain potentials and unbound pronouns. Journal of Memory and Language, 76, 1-28. https://doi.org/10.1016/j.jml.2014.06.002

[125] Burkhardt, P. (2006). Inferential bridging relations reveal distinct neural mechanisms: Evidence from event-related brain potentials. Brain and Language, 98(2), 159-168. https://doi.org/10.1016/j.bandl.2006.04.005

[126] Schumacher, P. B., \& Hung, Y.-C. (2012). Positional influences on information packaging: Insights from topological fields in German. Journal of Memory and Language, 67(2), 295-310. https://doi.org/10.1016/j.jml.2012.05.006

[127] Schumacher, P. B. (2012). Context in neurolinguistics. In R. Finkbeiner, J. Meibauer, \& P. B. Schumacher (Eds.), What is a Context?: Linguistic Approaches and Challenges (pp. 33-53). Amsterdam/Philadelphia, John 
Benjamins Publishing. https://books.google.it/books?id=gcl-N7FZPA4C\&lpg= PA33\&ots $=$ nhHo0v3V1a\&lr\&hl=it\&pg $=\mathrm{PA} 33 \# \mathrm{v}=$ onepage $\& \mathrm{q} \& \mathrm{f}=$ false

[128] Masia, V., Canal, P., Ricci, I., Vallauri, E. L., \& Bambini, V. (2017). Presupposition of new information as a pragmatic garden path: Evidence from Event-Related Brain Potentials. Journal of Neurolinguistics, 42, 31-48. https://doi.org/10.1016/j.jneuroling.2016.11.005

[129] Domaneschi, F., Canal, P., Masia, V., Lombardi Vallauri, E., \& Bambini, V. (2018). N400 and P600 modulation in presupposition accommodation: The effect of different trigger types. Journal of Neurolinguistics, 45, 13-35. https://doi.org/10.1016/j.jneuroling.2017.08.002

[130] Hasson, U., Egidi, G., Marelli, M., \& Willems, R. M. (2018). Grounding the neurobiology of language in first principles: The necessity of non-languagecentric explanations for language comprehension. Cognition, 180, 135-157. https://doi.org/10.1016/j.cognition.2018.06.018

[131] Egorova, N., Shtyrov, Y., \& Pulvermüller, F. (2013). Early and parallel processing of pragmatic and semantic information in speech acts: neurophysiological evidence. Frontiers in Human Neuroscience, 7, 86. https://doi.org/10.3389/fnhum.2013.00086

[132] Austin, J. L. (1962). How to do things with words. Oxford, Oxford University Press. https://books.google.it/books?id=XnRkQSTUpmgC

[133] Searle, J. (1979). Expression and Meaning: Studies in the Theory of Speech Acts. Cambridge, Cambridge University Press. https://books.google.it/books? id $=1 \mathrm{WqLLMG} 1 \mathrm{XiIC}$

[134] Coulson, S., \& Lovett, C. (2010). Comprehension of non-conventional indirect requests: An event-related brain potential study. Italian Journal of Linguistics, 22(1), 107-124. http:// www. italian - journal - linguistics . com / wp - content / uploads/coulsonlovett.pdf

[135] Gisladottir, R. S., Chwilla, D. J., \& Levinson, S. C. (2015). Conversation electrified: ERP correlates of speech act recognition in underspecified utterances. PLOS ONE, 10(3), 1-24. https://doi.org/10.1371/journal.pone. 0120068

[136] Tomasello, R., Kim, C., Dreyer, F. R., Grisoni, L., \& Pulvermüller, F. (2019). Neurophysiological evidence for rapid processing of verbal and gestural information in understanding communicative actions. Scientific Reports, 9(1), 1-17. https://doi.org/10.1038/s41598-019-52158-w

[137] Gisladottir, R. S., Bögels, S., \& Levinson, S. C. (2018). Oscillatory brain responses reflect anticipation during comprehension of speech acts in spoken dialog. Frontiers in Human Neuroscience, 12, 34. https://doi.org/10.3389/fnhum.2018.00034 
[138] Bögels, S., Kendrick, K. H., \& Levinson, S. C. (2015). Never say no... How the brain interprets the pregnant pause in conversation. PLOS ONE, 10(12), 1-15. https://doi.org/10.1371/journal.pone.0145474

[139] Bögels, S., Kendrick, K. H., \& Levinson, S. C. (2020). Conversational expectations get revised as response latencies unfold. Language, Cognition and Neuroscience, 35(6), 766-779. https://doi .org/10.1080/23273798.2019. 1590609

[140] Cummings, L. (2017). Research in Clinical Pragmatics. Springer International Publishing. https://books.google.it/books?id=r5TZDQAAQBAJ

[141] Cummings, L. (2014). Pragmatic Disorders. Springer International Publishing.

[142] Thoma, P., \& Daum, I. (2006). Neurocognitive mechanisms of figurative language processing-Evidence from clinical dysfunctions. Neuroscience \& Biobehavioral Reviews, 30(8), 1182-1205. https : / / doi . org / https : //doi.org/10.1016/j.neubiorev.2006.09.001

[143] Martin, I., \& McDonald, S. (2003). Weak coherence, no theory of mind, or executive dysfunction? Solving the puzzle of pragmatic language disorders. Brain and Language, 85(3), 451-466. https://doi.org/10.1016/S0093-934X(03) 00070-1

[144] Stemmer, B. (1999). Discourse Studies in Neurologically Impaired Populations: A Quest for Action. Brain and Language, 68(3), 402-418. https://doi.org/10. 1006/brln.1999.2120

[145] Bosia, M., Bechi, M., Bosinelli, F., Politi, E., Buonocore, M., Spangaro, M., Bianchi, L., Cocchi, F., Guglielmino, C., \& Cavallaro, R. (2019). From cognitive and clinical substrates to functional profiles: Disentangling heterogeneity in schizophrenia. Psychiatry Research, 271, 446-453. https://doi.org/10.1016/ j.psychres.2018.12.026

[146] Harvey, P. D., Bowie, C. R., \& Friedman, J. I. (2001). Cognition in schizophrenia. Current Psychiatry Reports, (3), 423-428. https : //doi.org/10.1007/s11920-996-0038-7

[147] Covington, M. A., He, C., Brown, C., Naçi, L., McClain, J. T., Fjordbak, B. S., Semple, J., \& Brown, J. (2005). Schizophrenia and the structure of language: The linguist's view. Schizophrenia Research, 77(1), 85-98. https://doi.org/10. 1016/j.schres.2005.01.016

[148] Bambini, V., Arcara, G., Bechi, M., Buonocore, M., Cavallaro, R., \& Bosia, M. (2016). The communicative impairment as a core feature of schizophrenia: Frequency of pragmatic deficit, cognitive substrates, and relation with quality of life. Comprehensive Psychiatry, 71, 106-120. https://doi.org/10.1016/j. comppsych.2016.08.012

[149] Bambini, V., Arcara, G., Bosinelli, F., Buonocore, M., Bechi, M., Cavallaro, R., \& Bosia, M. (2020). A leopard cannot change its spots: A novel pragmatic 
account of concretism in schizophrenia. Neuropsychologia, 139, 107332. https: //doi.org/10.1016/j.neuropsychologia.2020.107332

[150] Strandburg, R. J., Marsh, J. T., Brown, W. S., Asarnow, R. F., Guthrie, D., Harper, R., Yee, C. M., \& Nuechterlein, K. H. (1997). Event-related potential correlates of linguistic information processing in schizophrenics. Biological Psychiatry, 42(7), 596-608. https://doi.org/10.1016/S0006-3223(96)00410-6

[151] Iakimova, G., Passerieux, C., Laurent, J.-P., \& Hardy-Bayle, M.-C. (2005). ERPs of metaphoric, literal, and incongruous semantic processing in schizophrenia. Psychophysiology, 42(4), 380-390. https : //doi.org/10.1111/j.1469-8986.2005.00303.x

[152] Schneider, S., Wagels, L., Haeussinger, F. B., Fallgatter, A. J., Ehlis, A.-C., \& Rapp, A. M. (2015). Haemodynamic and electrophysiological markers of pragmatic language comprehension in schizophrenia. The World Journal of Biological Psychiatry, 16(6), 398-410. https : //doi.org/10.3109/15622975.2015.1019359

[153] Wang, K., Cheung, E. F. C., Gong, Q., \& Chan, R. C. K. (2011). Semantic Processing Disturbance in Patients with Schizophrenia: A Meta-Analysis of the N400 Component. PLOS ONE, 6(10), 1-8. https://doi.org/10.1371/journal. pone. 0025435

[154] Hirano, S., Spencer, K. M., Onitsuka, T., \& Hirano, Y. (2020). LanguageRelated Neurophysiological Deficits in Schizophrenia [PMID: 31741393]. Clinical EEG and Neuroscience, 51(4), https://doi.org/10.1177/1550059419886686, 222-233. https://doi.org/10.1177/1550059419886686

[155] Swaab, T. Y., Boudewyn, M. A., Long, D. L., Luck, S. J., Kring, A. M., Ragland, J. D., Ranganath, C., Lesh, T., Niendam, T., Solomon, M., Mangun, G. R., \& Carter, C. S. (2013). Spared and Impaired Spoken Discourse Processing in Schizophrenia: Effects of Local and Global Language Context. Journal of Neuroscience, 33(39), 15578-15587. https://doi.org/10.1523/JNEUROSCI.0965-13.2013

[156] Boudewyn, M. A., Carter, C. S., Long, D. L., Traxler, M. J., Lesh, T. A., Mangun, G. R., \& Swaab, T. Y. (2017). Language context processing deficits in schizophrenia: The role of attentional engagement. Neuropsychologia, 96, 262-273. https://doi.org/10.1016/j.neuropsychologia.2017.01.024

[157] Gold, R., Faust, M., \& Goldstein, A. (2010). Semantic integration during metaphor comprehension in Asperger syndrome. Brain and Language, 113(3), 124-134. https://doi.org/10.1016/j.bandl.2010.03.002

[158] Del Goleto, S., Kostova, M., \& Blanchet, A. (2016). Impaired context processing during irony comprehension in schizotypy: An ERPs study. International Journal of Psychophysiology, 105, 17-25. https : //doi.org/10.1016/j.ijpsycho.2016.04.009 
[159] Li, X., Pesonen, J., Haimi, E., Wang, H., \& Astikainen, P. (2020). Electrical brain activity and facial electromyography responses to irony in dysphoric and non-dysphoric participants. Brain and Language, 211, 104861. https://doi.org/ 10.1016/j.bandl.2020.104861

[160] Hoeks, J. C., \& Brouwer, H. (2014). Electrophysiological research on conversation and discourse. In T. Holtgraves (Ed.), The Oxford Handbook of Language and Social Psychology (pp. 365-386). Oxford, Oxford University Press. https://books.google.it/books?id=nWf0AwAAQBAJ

[161] Gibbs, R. W. (1980). Spilling the beans on understanding and memory for idioms in conversation. Memory \& Cognition, 8(2), 149-156. https://doi.org/10.3758/BF03213418

[162] Bentin, S., McCarthy, G., \& Wood, C. C. (1985). Event-related potentials, lexical decision and semantic priming. Electroencephalography and Clinical Neurophysiology, 60(4), 343-355. https :// doi .org/10 . 1016/0013 4694(85)90008-2

[163] Van Petten, C., \& Kutas, M. (1990). Interactions between sentence context and word frequency in event-related brain potentials. Memory \& Cognition, 18(4), 380-393. https://doi.org/10.3758/BF03197127

[164] Lai, V. T., Howerton, O., \& Desai, R. H. (2019). Concrete processing of action metaphors: Evidence from ERP. Brain Research, 1714, 202-209. https://doi. org/10.1016/j.brainres.2019.03.005

[165] Canal, P., Bischetti, L., Bertini, C., Ricci, I., Lecce, S., \& Bambini, V. N400 differences between mental and physical metaphors: the role of Theories of Mind. Conference presentation at the 8th Experimental Pragmatics conference (XPRAG), Edinburgh, June 19-21. 2019. https://www.xprag2019.ppls.ed.ac.uk/ abstracts/canal.pdf

[166] Canal, P., Ranieri, G., Bischetti, L., Tonini, E., Bertini, C., Ricci, I., Schaeken, W., \& Bambini, V. Bridging concepts in different modalities: The N400 of verbal and multimodal metaphor processing. Conference presentation at the 13th conference for the Association for Researching and Applying Metaphor (RaAM), virtual conference, 18-21 June. 2020. https://media.inn.no/Mediasite/ Channel/raam2020/watch/9f5c9dafa72d41b0a2ab78c4ca86e3341d

[167] Bornkessel-Schlesewsky, I., \& Schlesewsky, M. (2008). An alternative perspective on "semantic P600" effects in language comprehension. Brain Research Reviews, 59(1), 55-73. https://doi.org/10.1016/j.brainresrev.2008.05. 003

[168] Daneman, M., \& Carpenter, P. A. (1980). Individual differences in working memory and reading. Journal of Memory and Language, 19(4), 450-466. https: //doi.org/10.1016/S0022-5371(80)90312-6 
[169] Holcomb, P. J., Coffey, S. A., \& Neville, H. J. (1992). Visual and auditory sentence processing: A developmental analysis using event-related brain potentials. Developmental Neuropsychology, 8(2-3), 203-241. https://doi.org/10.1080/87565649209540525

[170] Nieuwland, M. S., Ditman, T., \& Kuperberg, G. R. (2010). On the incrementality of pragmatic processing: An ERP investigation of informativeness and pragmatic abilities. Journal of Memory and Language, 63(3), 324-346. https://doi.org/10.1016/j.jml.2010.06.005

[171] Martin, A. E. (2020). A Compositional Neural Architecture for Language. Journal of Cognitive Neuroscience, 32(8), 1407-1427. https://doi.org/10.1162/jocn_a_01552

[172] Noveck, I. A., \& Posada, A. (2003). Characterizing the time course of an implicature: An evoked potentials study. Brain and Language, 85(2), 203-210. https://doi.org/10.1016/S0093-934X(03)00053-1

[173] Spychalska, M., Kontinen, J., \& Werning, M. (2016). Investigating scalar implicatures in a truth-value judgement task: evidence from event-related brain potentials. Language, Cognition and Neuroscience, 31(6), 817-840. https://doi.org/10.1080/23273798.2016.1161806

[174] Nieuwland, M. S., \& Kuperberg, G. R. (2008). When the truth is not too hard to handle: an event-related potential study on the pragmatics of negation. Psychological Science, 19(12), 1213-1218. https://doi.org/10.1111/j.14679280.2008.02226.x

[175] Xiang, M., Grove, J., \& Giannakidou, A. (2016). Semantic and pragmatic processes in the comprehension of negation: An event related potential study of negative polarity sensitivity. Journal of Neurolinguistics, 38, 71-88. https://doi.org/10.1016/j.jneuroling.2015.11.001

[176] Moreno, E. M., Casado, P., \& Martın-Loeches, M. (2016). Tell me sweet little lies: An event-related potentials study on the processing of social lies. Cognitive, Affective, \& Behavioral Neuroscience, 16(4), 616-625. https://doi.org/10.3758/ s13415-016-0418-3

[177] Delogu, F., Jachmann, T., Staudte, M., Vespignani, F., \& Molinaro, N. (2020). Discourse expectations are sensitive to the question under discussion: Evidence from ERPs. Discourse Processes, 57(2), 122-140. https:// doi.org/10.1080/ 0163853X.2019.1575140

[178] Dimitrova, D. V., Stowe, L. A., Redeker, G., \& Hoeks, J. C. (2012). Less is not more: Neural responses to missing and superfluous accents in context. Journal of Cognitive Neuroscience, 24(12), 2400-2418. https://doi.org/10.1162/jocn_ a_00302 